\title{
Sublingual Immunotherapy for Aeroallergens: Optimal Patient Dosing, Regimen and Duration
}

\section{Harold S. Nelson, MD}

\section{Address}

National Jewish Health and University of Colorado Denver School of Medicine, 1400 Jackson St, Denver, C0 80206, USA

Email: nelson@njhealth.org

Published online: 11 February 2014

(C) Springer International Publishing AG 2014

Keywords Immunotherapy · Sublingual immunotherapy · Dosing • Duration · Frequency · Asthma - Allergic rhinitis - Subcutaneous immunotherapy

\section{Opinion Statement}

Sublingual immunotherapy (SLIT) is a proven effective treatment for allergic rhinitis and allergic asthma. It can be disease-modifying: preventing the development of new sensitivities in monosensitized patients, preventing progression from allergic rhinitis to asthma, and providing long-lasting benefit after discontinuation of a successful course of treatment. The efficacy of sublingual immunotherapy, like that of subcutaneous immunotherapy (SCIT), is dependent on proper administration. This includes appropriate dosing, frequency, and duration of therapy. The current evidence for SLIT tablets is that daily administration of a dose equivalent to the monthly SCIT maintenance dose is appropriate. The appropriate doses for SLIT drops have not been adequately defined and may be the same or more than SLIT tablets. The optimal frequency of administration of SLIT appears to be daily. The optimal duration of SLIT for insuring disease modification appears to be 3 or 4 years. The initiation of SLIT at the maintenance dose appears safe if performed under physician observation. Preliminary evidence supports administration of pollen extracts only before and during the season, but further long-term follow-up is needed to ensure adequate disease modification. There are no studies to support the simultaneous administration of more than two non-cross-reacting allergens by SLIT.

\section{Introduction}

Large clinical trials $[1,2,3 \bullet, 4]$ and meta-analyses $[5$, the treatment of allergic rhinitis and allergic asthma. 6] have now confirmed the effectiveness of SLIT for Like SCIT, SLIT when appropriately administered 
modifies the underlying allergic status as demonstrated by reducing the development of new sensitivities in monosensitized patients $[7 \bullet \bullet]$, retarding the development of asthma in patients with allergic rhinitis [8], and inducing prolonged clinical remissions following its discontinuation $[9 \bullet]$. Although good results with SLIT have been reported with widely divergent regimens [10], more recent large studies have helped defined the dosing frequency and duration for optimal results.

\section{Optimal Dosing}

The clinical response to subcutaneous injection immunotherapy (SCIT) is exquisitely dependent on the dose of extract delivered. A reduction of 80-95\% of the dose that provides a good therapeutic response can result in marked reduction or even complete loss of that response [11]. Cox et al. in 2005 reviewed the available literature on sublingual immunotherapy (SLIT) [10]. They identified 57 studies that provided doses used for SLIT expressed in micrograms of major allergen. The individual doses employed varied by 35,000 -fold and cumulative monthly SLIT doses varied from 0.017 to $>500$ times the customary SCIT monthly maintenance dose. For most of these studies there was no justification offered for the doses employed. The 43 randomized studies (39 placebo-controlled) were categorized by the monthly cumulative dose delivered by SLIT, in comparison to the monthly maintenance dose given by the same investigators by SCIT, into low-dose $(<1$ to 5 times), intermediate-dose ( 6 to 50 times) and high-dose (>50 times). There was no clear dose response, since improvements in both symptom and medication scores were reported in 11/16 low-dose, 4/7 intermediate-dose, and $3 / 7$ high-dose regimens used to treat seasonal allergic rhinitis. A subsequent meta-analysis of SLIT included 49 studies. [5] This report found highly significant reductions in symptom and medication scores with SLIT. When they divided dosing into $<5$ mcg major allergen, 5-20 mcg major allergen and $>20$ mcg major allergen, they found that the clinical outcome was similar with all three dosing ranges.

Since the studies that contributed to the above reviews, other adequatelypowered, randomized, double-blind studies examining two or more doses have been conducted with several allergen extracts (Table 1). In addition, studies examining the safety of very high doses have been conducted with timothy and short ragweed tablets (Table 2). Although the differences between doses are not always significant, the highest doses studied usually proved better when compared against placebo than lower doses. For short ragweed liquid, the dose containing $48 \mathrm{mcg} \mathrm{Amb}$ a 1 administered daily performed better than that containing $4.8 \mathrm{mcg}$ [12]. A short ragweed tablet was studied twice $[3 \bullet, 13]$ and each time the one containing $12 \mathrm{mcg}$ of Amb a 1 was superior to the one containing $6 \mathrm{mcg}$, while the one containing $1.5 \mathrm{mcg}$ was ineffective. The same tablet was studied for high-dose safety and found to have unacceptable side effects at a dose containing $50 \mathrm{mcg}$ Amb a 1[14]. Another short ragweed tablet, administered three times weekly, was more effective at a reported dose of $480 \mathrm{mcg}$ Amb a 1 than either $160 \mathrm{mcg}$ or $320 \mathrm{mcg}$ [15].

A three-grass liquid was compared at two doses reported to be cumulatively 85 and 375 times the customary cumulative SCIT dose [16]. The higher 


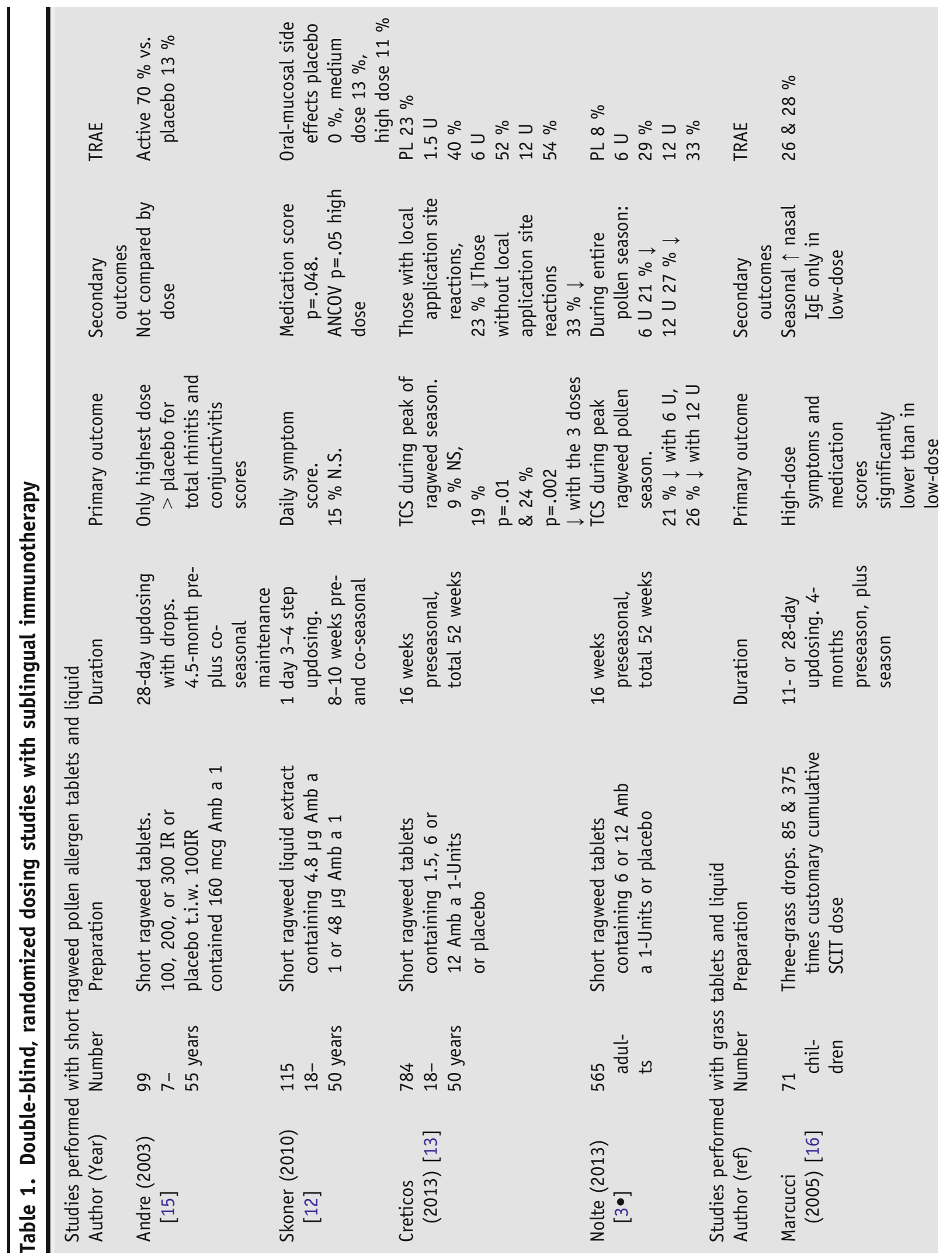



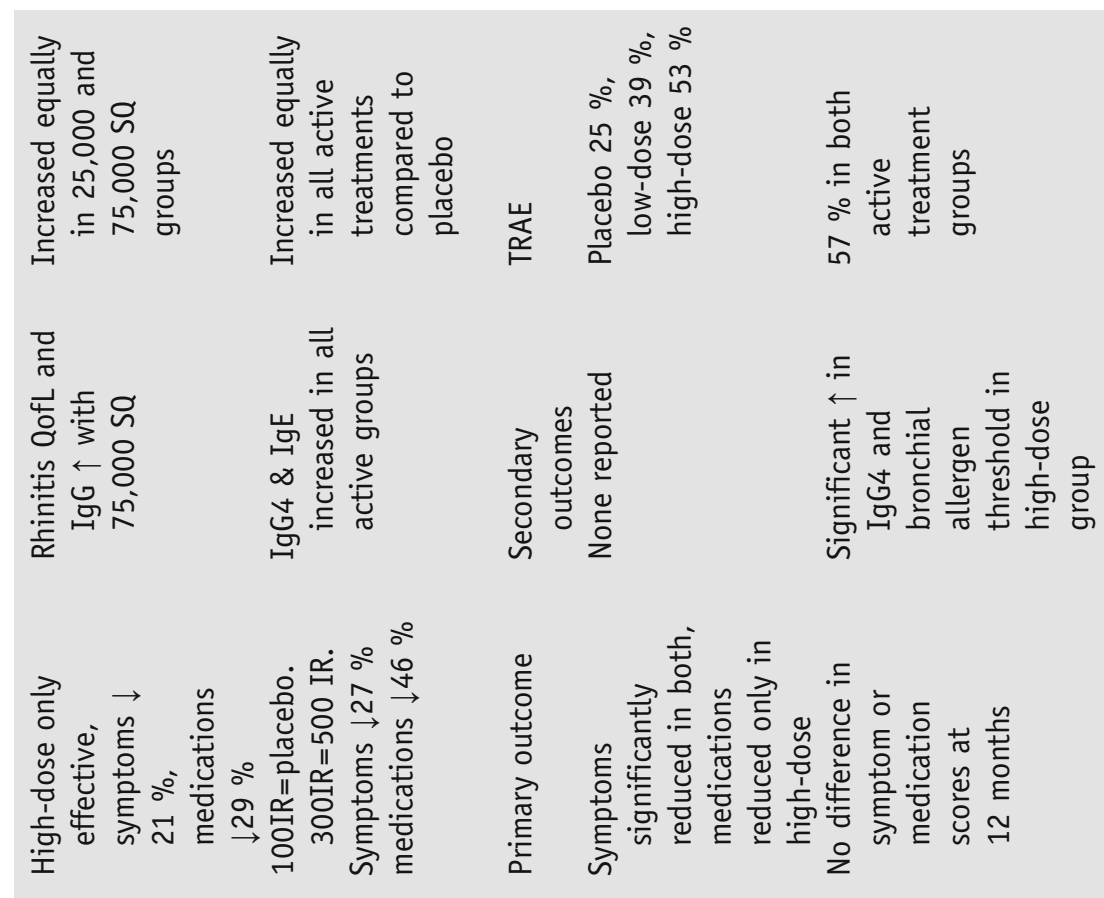

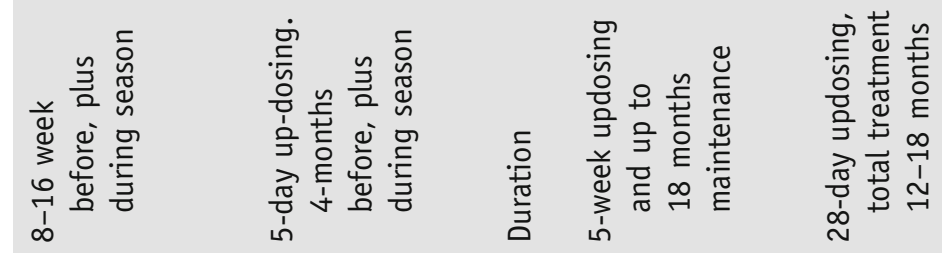

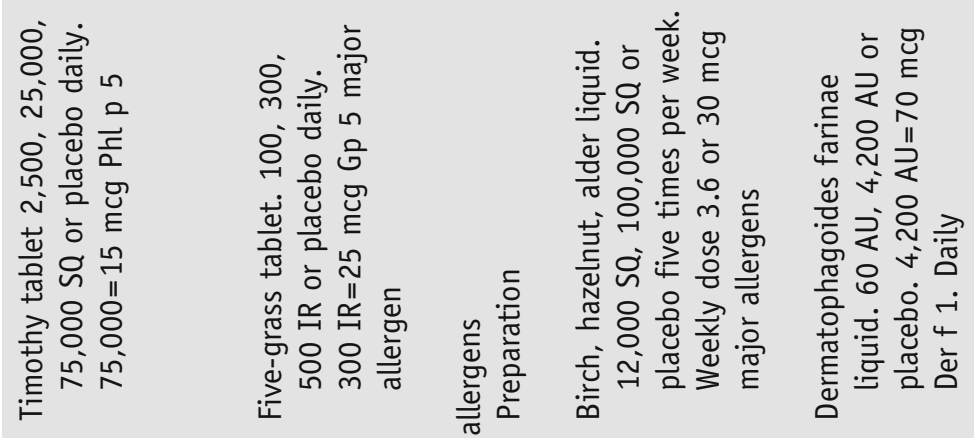

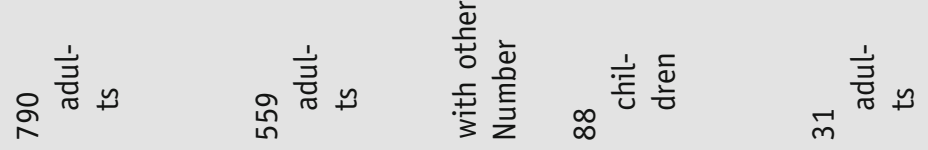

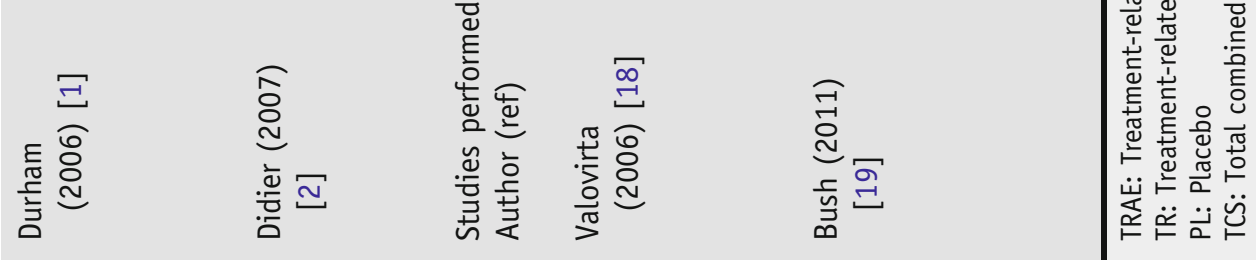




\begin{tabular}{|c|c|c|c|c|c|}
\hline $\begin{array}{l}\text { Author } \\
\text { (reference) }\end{array}$ & Allergen & Number & Doses & $\begin{array}{l}\text { TRAE-all } \\
\text { moderate } \\
\text { severe }\end{array}$ & Comment \\
\hline $\begin{array}{l}\text { Kleine-Tebbe } \\
\text { (2006) [17] }\end{array}$ & $\begin{array}{l}\text { Timothy tablet } \\
75,000=15 \mathrm{mcg} \\
\text { Phl p } 5\end{array}$ & $\begin{array}{l}\text { Nine active, three } \\
\text { placebo each } \\
\text { dose. Treated } \\
28 \text { days }\end{array}$ & $\begin{array}{l}\text { Placebo } \\
25,000 \mathrm{SQ} \\
75,000 \mathrm{SQ} \\
150,000 \mathrm{SQ} \\
300,000 \mathrm{SQ} \\
500,000 \mathrm{SQ} \\
750,000 \mathrm{SQ} \\
1,000,000 \mathrm{SQ}\end{array}$ & $\begin{array}{l}19 \%-10 \% \\
22 \%-22 \% \\
67 \%-22 \% \\
67 \%-44 \% \\
100 \%-22 \% \\
100 \%-44 \% \\
89 \%-33 \% \\
100 \%-33 \% \\
\text { All Moderate } \\
\text { Severe }\end{array}$ & $\begin{array}{l}\text { Throat- irritation } \\
\text { and mouth- } \\
\text { edema frequent } \\
300,000 \mathrm{SQ} \\
\text { and above. No } \\
\text { serious or } \\
\text { systemic } \\
\text { reactions }\end{array}$ \\
\hline Nayak (2012) [14] & $\begin{array}{l}\text { Short-ragweed } \\
\text { tablet. } 1 \mathrm{Amb} \\
\text { a } 1-U=1 \mathrm{mcg} \\
\text { Amb a } 1\end{array}$ & $\begin{array}{l}\text { Nine active, three } \\
\text { placebo each } \\
\text { dose. Treated } \\
28 \text { days }\end{array}$ & $\begin{array}{l}3 \mathrm{Amb} \text { a } 1-U \\
6 \mathrm{Amb} \text { a } 1-U \\
12 \mathrm{Amb} \text { a } 1-U \\
24 \mathrm{Amb} \text { a } 1-U \\
50 \mathrm{Amb} \text { a } 1-U \\
100 \mathrm{Amb} \text { a } 1-U\end{array}$ & $\begin{array}{l}78 \%-22 \%-0 \% \\
67 \%-0 \%-0 \% \\
56 \%-11 \%-0 \% \\
89 \%-56 \%-22 \% \\
50 \%-25 \%-25 \% \\
\text { Stopped after } 4 \\
\text { subjects } \\
\text { No administered }\end{array}$ & $\begin{array}{l}\text { No serious TRAE, } \\
\text { no severe or } \\
\text { life-threatening } \\
\text { systemic } \\
\text { reactions }\end{array}$ \\
\hline
\end{tabular}

dose was significantly more effective than the lower dose. Two grass tablets have been studied, one containing only timothy [1] and the other containing five cross-reacting grasses [2]. A timothy tablet containing $15 \mathrm{mcg}$ of Phl p 5 administered daily was superior to placebo, whereas timothy tablets containing 0.5 and $5 \mathrm{mcg}$ Phl p 5 were not [1]. A study of high-dose safety with the same tablet revealed increasing side effects at 30 or $60 \mathrm{mcg}$ [17]. The fivegrass tablet was administered daily at three doses. The dose containing $8 \mathrm{mcg}$ of group 5 allergen was ineffective, while doses containing either $25 \mathrm{mcg}$ or $42 \mathrm{mcg}$ were equally effective [2].

A study involving liquid extracts of birch/hazelnut/alder administered five times a week revealed more consistent efficacy with a dose containing 6 mcg of major allergens compared to one containing 0.7 mcg [18]. A small study with house dust mite extract produced no effect on symptoms or medication use, but daily administration of a dose containing $70 \mathrm{mcg}$ of Der $\mathrm{f} 1 \mathrm{im}$ proved the bronchial threshold to allergens, whereas one containing $1 \mathrm{mcg}$ Der f 1 did not [19].

In all except one [19] of the dose-ranging studies, treatment-related adverse reactions were more common with the active treatment than with the placebo. In almost all cases they were limited to mild-to-moderate application-site pruritus and sometimes swelling. The only local reaction considered serious was one episode of uvula edema [1]. Systemic reactions of rhinitis, 
urticaria or asthma were reported occasionally $[2,15]$ but were never serious, and no life threatening reactions were reported.

\section{Treatment Regimens}

Well-defined doses have been demonstrated for SLIT grass and ragweed tablets. For both, daily sublingual administration of a dose that has been shown to be effective as a once-monthly SCIT maintenance dose has produced significant improvement versus placebo. Higher doses have been demonstrated to either have an unacceptable rate of side effects [14, 17], or to have no greater efficacy [2]. The optimum dose with liquid extracts is less clear. A relatively low-dose tree extract was effective [18], as were moderately high doses of ragweed [4] and house dust mite [19] and a seemingly very high dose of grass [15]. However, in three of these studies, the alternative dose studied was only $1 / 10$ th that of the dose found effective, so intermediate doses might have been equally effective if they had been studied.

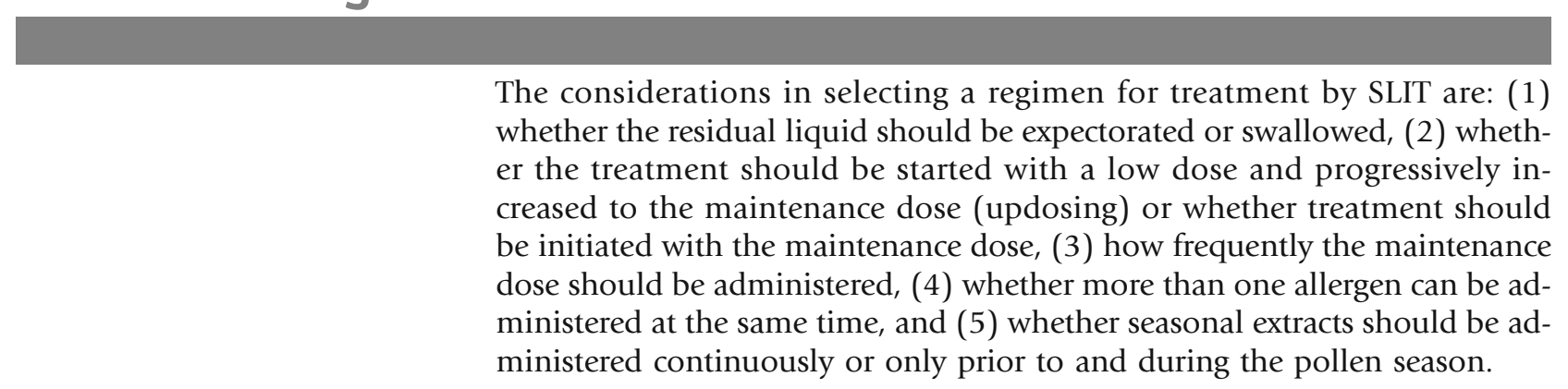

\section{Sublingual-Swallow Versus Sublingual-Spit}

With SLIT, the liquid or tablets are placed under the tongue and the material is held there for 1-3 minutes. It is then possible to expectorate the remaining liquid (sublingual-spit) or to swallow the residual (sublingual-swallow). Since oral immunotherapy requires larger doses than SLIT to be effective, the contribution to the clinical response from the swallowed portion is probably small. A study based on radiolabelled major allergens of Parietaria found that approximately $30 \%$ of the radioactivity was expectorated with sublingual-spit [20]. The investigators therefore recommended swallowing the residual.

SCIT is always initiated with a series of increasing doses that may be administered one or several times a week or more rapidly in cluster or rush protocols. Initially, a similar build-up of dosing was employed with SLIT, although usually treatment was administered several times per week. Later, very rapid escalating regimens were employed with maintenance doses being achieved in 1 hour or less $[21,22]$. Finally, with the introduction of timothy grass tablets, updosing was no longer practiced and therapy was initiated with the maintenance dose [1]. In the absence of head-to-head comparisons, it is 
not possible to determine whether there is a difference in the rate of adverse reactions between the different regimens. However, it is clear that reactions at the application site are common whether initiation of therapy is accomplished over weeks, an hour, or immediately. Thus, in a high-dose grass SLIT study that employed a 6-week, three-times-a-week updosing regimen, 380 mild, local reactions occurred in 28 subjects [23]. With an ultra-rush protocol consisting of five doses at 10-minute intervals, $42 \%$ of subjects receiving high-dose house dust mite or grass extract experienced mild local reactions [24]. With high-dose grass tablets, initiation of treatment was without buildup with the timothy tablet, and with three doses over 3 days with the fivegrass tablets $[1,2]$. Oral pruritus, mouth edema and throat irritation were reported in 46,18 and $9 \%$ of subjects with timothy tablets [1], and 26, 5 and $9 \%$ with the five-grass tablets, respectively [2]. The prevalence of side effects was less with the five-grass mixtures containing $25 \mathrm{mcg}$ of major allergens than with the timothy tablets containing 15 mcg of major allergens, suggesting a protective effect of updosing, but head-to-head studies would be required to determine if this conclusion is valid.

Studies with SLIT have reported dosing intervals ranging from daily to weekly [10]. Bordignon and Parmiani administered SLIT monotherapy to 90 patients with a variety of biologically standardized extracts according to two regimens: one drop of the top dose daily, or five drops three times weekly (t.i.w.) [24]. The primary outcome was change in titrated skin prick tests that were performed at baseline and once yearly for 4 years. After 4 years, all subjects had a reduction in skin reactivity, but the reduction in those receiving daily SLIT was significantly $(\mathrm{p}<0.001)$ greater even though they had received less than half the amount of allergens of those treated t.i.w. Furthermore, the decrease in skin reactivity occurred earlier in those receiving daily treatment and they were nearly twice as likely to have reduced their use of symptomatic medication by greater than $50 \%(\mathrm{p}<0.0001)$. It is possible that the dosing frequency employed explains some otherwise puzzling negative results with SLIT [25-27]. Smith treated 91 patients with a five-grass extract containing in the maintenance dose $72 \mathrm{mcg}$ of Lol p1 and $42 \mathrm{mcg}$ of Dac g 5, administered three times weekly [25]. Despite this high-dose SLIT, there was no difference between active and placebo-treated patients after the first year. Two negative studies were conducted in the Netherlands [26, 27]. The first treated 168 children with either placebo or high-dose grass $(21$ mcg Lol p 5) extract twiceweekly for 2 years, while the second treated 251 children with placebo or moderate-dose house dust mite (2 mcg Der p 1) twice-weekly for two years. Neither study demonstrated any difference between active and placebo groups.

Whereas most SCIT in the US is administered as a mixture of multiple, unrelated allergens, SLIT as practiced in Europe is typically monotherapy. There is one randomized study from Italy in which 48 patients sensitized to both birch and grass were treated with monotherapy to each, or to combined SLIT with both extracts, or were untreated controls [28]. This was an open study of 
4 years duration. Patients treated with monotherapy improved, compared to untreated patients during both the same and unrelated pollen seasons. The patients receiving both grass and birch responded during both pollen seasons, but given that this was an open, unblinded study, the results are difficult to interpret. A US study examined co-administration of SLIT to grass and house dust mite extracts. [29] Treated patients had fewer symptoms and medication use during the grass pollen season, and reduced response to grass and house dust mite extracts on skin prick testing and nasal challenge. The only study that examined the response to an allergen administered alone or combined with multiple other allergens was conducted in 56 subjects who were randomized to either timothy at a dose of $19 \mathrm{mcg}$ Phl p 5, or to the same dose combined with nine non-cross-reacting pollen extracts or placebo [30]. In this study, outcomes correlating with clinical improvement (titrated nasal challenge and titrated prick skin tests) and reflecting generation of regulatory $\mathrm{T}$ cells (allergen-specific IgG4) were all significantly positive versus placebo in the timothy monotherapy group; only the titrated prick skin test was significant compared with placebo in the multiple allergen group, and this outcome was less significant than in the timothy monotherapy group.

The safety comparisons of single- versus multiple-allergen SLITs have been reported in studies performed in Europe. Most of the multiple-allergen SLIT consisted of only two allergen extracts. Nevertheless, there were no increases in the occurrence of reactions with single-versus multiple-allergen SLIT [31].

\section{Continuous Versus Pre- and Co-Seasonal Treatment for Pollen Allergy}

SCIT, whether for seasonal or perennial allergens, is customarily administered on a continuous basis for at least 3 to 4 years. The rationale for administering SCIT for seasonal allergens on a continuous schedule includes the fact that most US patients are allergic to several allergens, which could extend the period of administration beyond just before and during a single pollen season. Also, once patients reach maintenance, the interval between injections can be extended to a month without the necessity of an annual preseasonal period of weekly injections for updosing, as required with non-continuous treatment. Although SLIT in Europe has typically been administered as monotherapy and the period of updosing has been greatly shortened or even eliminated, many studies have administered pollen extracts continuously over several years $[9 \bullet, 32]$. The continuous administration of birch for 3.5 years was followed by fully persisting benefit the next year without further SLIT [32], and 3 years of continuous treatment with timothy SLIT tablets resulted in persisting benefit for the next 2 years without further treatment $\left[9^{*}\right]$.

On the other hand, 3-year studies with pre- and co-seasonal [33•] or just co-seasonal [34] treatment with SLIT have also reported persisting clinical remission in the first year after SLIT was discontinued. In the study by Didier et al. [33•], there was no difference in the response during treatment or in the year following its discontinuation, whether administration of SLIT each year was initiated 2 or 4 months prior to the season. Another study with pre- and co-seasonal SLIT for three seasons in children with grass-induced allergic rhi- 
nitis demonstrated a significant decrease in the development of asthma in the treated children [35].

Two studies directly compared pre- and co-seasonal or only co-seasonal administration to continuous administration. In the study by Pajno et al. [36], continuous grass SLIT was begun in October and continued for 3 years, while the co-seasonal treatment was not started until March of each year. For the first 2 years, the clinical outcomes favored the group with continuous treatment, but by the third year there were no significant differences between the two regimens. In the study by Stelmach et al. [37], the treatment in the continuous, the pre-and co-seasonal and the placebo groups all began 8 weeks before the first pollen season and continued for 2 years. There were no differences among the three treatment groups the first year. In the second year, both active SLIT groups showed significantly better results than the placebo group, and the preseasonal dose proved significantly better than the continuous for nasal symptoms.

\section{Conclusions on Treatment Regimens}

The current practice is to swallow the residual SLIT liquid after a 1-3 minute interval of holding the liquid under the tongue. Local side effects appear to be common whether or not updosing is employed, and evidence is lacking as to whether updosing will prevent the extremely rare systemic reactions occurring after the first dose. Therefore, updosing may be considered optional. The available evidence, including one direct comparison, recommends daily over less-than-daily administration. The only study that administered more than two allergens simultaneously suggested that administering multiallergen extracts reduces efficacy. The administration of pollen extracts only before and during the season, or perhaps only during the season, appears to be as effective as continuous administration during the period of active treatment. Further follow-up through a second year of treatment of patients who received the discontinuous dosing will reveal whether the long-term outcome is as satisfactory as in those who received continuous treatment.

\section{Duration of Treatment}

Three or 4 years of SCIT have been shown to induce a remission in allergic rhinitis symptoms due to grass, the effects persisting without decline for 3 years after maintenance immunotherapy was stopped [38]. Three years of SCIT in children with allergic rhinitis due to grass and/or birch reduced the incidence of the development of asthma, and this effect continued without diminution 7 years after the SCIT was discontinued [39]. Similarly, persistence of the effects after 3 or 4 years of SLIT has been demonstrated [ $9 \bullet$, $32,33 \bullet, 34]$, with the reduction in symptoms persisting when assessed 1 $[32,33 \bullet, 34]$ or $2[9 \bullet]$ years after SLIT was stopped. The most impressive study was in 78 adults with house dust mite sensitivity, with both allergic rhinitis and bronchial sensitivity to methacholine, and with or without asthma [7]. Fifty-seven of the subjects were randomized to receive SLIT with house dust mite extract continuously for 3, 4 or 5 years. Each group was then followed until there was a $>50 \%$ return of symptoms, at which time they were retreated. The clinical remission persisted for 7 years following 3 years 
of SLIT, and for 8 years following either 4 or 5 years of SLIT. Similar patterns were observed for nasal eosinophils and methacholine sensitivity.

Conclusions on Duration of Treatment

The available evidence supports a 3- or 4-year duration of SLIT treatment, both for seasonal and perennial allergens.

\section{Compliance with Ethics Guidelines}

\section{Conflict of Interest}

Harold Nelson is a consultant to Merck and Circassia, received honoraria from Merck, and had travel/accommodations expenses covered or reimbursed by Merck.

Human and Animal Rights and Informed Consent

This article does not contain any studies with human or animal subjects performed by any of the authors.

\section{References and Recommended Reading}

Papers of particular interest, published recently, have been

highlighted as:

- Of importance

-• Of major importance

1. Durham SR, Yang WH, Pedersen MR, Johansen N, Rak S. Sublingual immunotherapy with once-daily grass allergen tablets: a randomized controlled trial in seasonal allergic rhinoconjunctivitis. J Allergy Clin Immunol. 2006;117:802-9.

2. Didier A, Malling H-J, Worm M, Horak F, Jager S, Montagut A, et al. Optimal dose, efficacy, and safety of once-daily sublingual immunotherapy with a 5grass pollen tablet for seasonal allergic rhinitis. J Allergy Clin Immunol. 2007;120:1338-45.

3.- Nolte H, Hebert J, Berman G, Gawchick S, White M, Kaur A, et al. Randomized controlled trial of ragweed allergy immunotherapy tablet efficacy and safety in North American adults. Ann Allergy Asthma Immunol. 2013;110:450-6.

This study defines an effective dose for a short ragweed SLIT tablet.

4. Creticos PS, Esch RE, Couroux P, Gentile DA, D'Angelo $\mathrm{P}$, Whitlow $\mathrm{B}$, et al. A randomized, double-blind, placebo-controlled, parallel trial of standardized short ragweed sublingual allergy immunotherapy liquid (SAIL) extract in adult subjects with ragweed-induced allergic rhinoconjunctivitis. Post 519, Annual Meeting American Academy of Allergy Asthma and Immunology. February 22-26, 2013, San Antonio, Texas.
5. Radulovic S, Wilson D, Calderon M, Durham S. Systematic reviews of sublingual immunotherapy (SLIT). Allergy. 2011;66:740-52.

6. Calamita Z, Saconato H, Pela AB, Atallah AN. Efficacy of sublingual immunotherapy in asthma: systematic review of randomized-clinical trials using the Cochrane Collaboration method. Allergy. 2006;61:1162-72.

7.• Marogna M, Spadolini I, Massolo A, Canonica GW, Passalacqua G. Long-lasting effects of sublingual immunotherapy according to its duration: a 15-year prospective study. J Allergy Clin Immunol. 2010;126:969-75.

A remarkable study demonstrating the duration of persisting clinical benefit for 3,4 and 5 years of SLIT treatment with house dust mite extract.

8. Marogna $\mathrm{M}$, Tomassetti D, Bernasconi A, Colombo F, Massola A, Businco AD, et al. Preventive effects of sublingual immunotherapy in childhood: an open randomized controlled study. Ann Allergy Asthma Immunol. 2008;101:206-11.

9. Durham SR, Emminger W, Kapp A, de Monchy JG, Rak S, Scadding GK, et al. SQ-standardized sublingual grass immunotherapy: confirmation of disease modification 2 years after 3 years of treatment in a 
randomized trial. J Allergy Clin Immunol.

2012;129:717-25.

This study demonstrates persisting clinical benefit for 2 years after discontinuation of 3-year treatment with SLIT timothy tablets.

10. Cox LS, Larenas Linnemann D, Nolte H, Weldon D, Finegold I, Nelson HS. Sublingual immunotherapy: a comprehensive review. J Allergy Clin Immunol. 2006;117:1021-35.

11. Nelson HS. Subcutaneous immunotherapy for optimal effectiveness. Immunol Allergy Clin N Am. 2011;31:211-26.

12. Skoner D, Gentile D, Bush R, Fasano MB, McLaughlin A, Esch RE. Sublingual immunotherapy in patients with allergic rhinoconjunctivitis caused by ragweed pollen. J Allergy Clin Immunol.

2010;125:660-6.

13. Creticos PS, Maloney J, Bernstein DI, Casale T, Kaur A, Fisher R, et al. Randomized controlled trial of a ragweed allergy immunotherapy tablet in North American and European adults. J Allergy Clin Immunol. 2013;131:1342-9.

14. Nayak AS, Atiee GJ, Dige E, Maloney J, Nolte H. Safety of ragweed sublingual allergy immunotherapy tablets in adults with allergic rhinoconjunctivitis. Allergy Asthma Proc. 2012;33:404-10.

15. Andre C, Perrin-Fayolle M, Grosclaude M, Couturier $\mathrm{P}$, Basset D, Cornillon J, et al. A double-blind placebo-controlled evaluation of sublingual immunotherapy with a standardized ragweed extract in patients with seasonal rhinitis. Evidence for a doseresponse relationship. Int Arch Allergy Immunol. 2003;131:111-8.

16. Marcucci F, Sensi L, Di Cara G, Incorvaia C, Frati F. Dose dependence of immunological response to sublingual immunotherapy. Allergy. 2005;60:952-6.

17. Kleine-Tebbe J, Ribel M, Herold DA. Safety of a SQstandardised grass allergen tablet for sublingual immunotherapy: a randomized, placebo-controlled trial. Allergy. 2006;61:181-4.

18. Valovirta E, Jacobsen L, Ljorring C, Koivikko A, Savolainen J. Clinical efficacy and safety of sublingual immunotherapy with tree pollen extract in children. Allergy. 2006;61:1177-83.

19. Bush RK, Swenson C, Fahlberg B, Evans MD, Esch R, Busse WW. House dust mite sublingual immunotherapy: results of a US trial. J Allergy Clin Immunol. 2011;127:974-81.

20. Passalacqua G, Villa G, Altrinetti V, Falagiani $P$, Canonica GW, Mariani G, et al. Sublingual swallow or spit? Allergy. 2001;56:578.

21. Rossi RE, Monasterolo G. A pilot study of feasibility of ultra-rush (20-25 minutes) sublingual-swallow immunotherapy in 679 patients (699 sessions) with allergic rhinitis and/or asthma. Int J Immunopathol Pharmacol. 2005;18:277-85.
22. Tripodi S, Di Rienzo Businco A, Benincori N, Scala G, Pingitore G. Safety and tolerability of ultra-rush induction, less than one hour, of sublingual immunotherapy in children. Int Arch Allergy Immunol. 2006;139:149-52.

23. Torres Lima M, Wilson D, Pitkin L, Roberts A, NouriAria K, Jacobson M, et al. Grass pollen sublingual immunotherapy for seasonal rhinoconjunctivitis: a randomized controlled trial. Clin Exp Allergy. 2002;32:507-14.

24. Bordignon V, Parmiani S. Variation of the skin endpoint in patients treated with sublingual specific immunotherapy. J Invest Allergol Clin Immunol. 2003;13:170-6.

25. Smith H, White P, Annila I, Poole J, Andre C, Frew A. Randomized controlled trial of high-dose sublingual immunotherapy to treat seasonal allergic rhinitis. J Allergy Clin Immunol. 2004;114:831-7.

26. Roder E, Berger MY, Hop WC, Bernstein RMD, de Groot H, van Wijk RG. Sublingual immunotherapy with grass pollen is not effective in symptomatic youngsters in primary care. J Allergy Clin Immunol. 2007; 119:892-8.

27. De Bot CMA, Moed H, Berger MY, Roder E, Hop WCJ, de Groot $\mathrm{H}$, et al. Sublingual immunotherapy not effective in house dust mite-allergic children in primary care. Pediatr Allergy Immunol. 2012;23:150-8.

28. Marogna M, Spadolini I, Massolo A, Zanon P, Berra D, Chiodini E, et al. Effects of sublingual immunotherapy for multiple or single allergens in polysensitized patients. Ann Allergy Asthma Immunol. 2007;98:274-80.

29. Swamy RS, Reshamwala N, Hunter T, Vissamsetti S, Santos CB, Baroody FM, et al. Epigenetic modifications and improved regulatory T-cell function in subjects undergoing dual sublingual immunotherapy. J Allergy Clin Immunol. 2012;130:21524.

30. Amar SM, Harbeck RJ, Sills M, Silveira LJ, O'Brien H, Nelson HS. Response to sublingual immunotherapy with grass pollen extract: monotherapy versus combination in a multiallergen extract. J Allergy Clin Immunol. 2009;124:150-6.

31. Agostinis F, Foglia C, Landi M, Cottini M, Lombardi C, Canonica GW, et al. The safety of sublingual immunotherapy with one or multiple pollen allergens in children. Allergy. 2008;63:1637-9.

32. Marogna M, Spadolini I, Massolo A, Canonica GW, Passalacqua G. Clinical, function, and immunologic effects of sublingual immunotherapy in birch pollinosis: a 3-year randomized controlled study. J Allergy Clin Immunol. 2005;115:1184-8.

33. Didier A, Malling H-J, Worm M, Horak F, Sussman G, Melac $M$, et al. Post-treatment efficacy of discontinuous treatment with 300 IR 5-grass pollen sublingual tablet in adults with grass pollen-induced 
allergic rhinoconjunctivitis. Clin Exp Allergy.

2013;43:568-77.

This study demonstrates persisting clinical improvement for 1 year after discontinuing 3 years of pre-coseasonal SLIT with five-grass tablets.

34. Ott H, Sieber J, Brehier R, Folster-Holst R, Kapp A, Klimek L, et al. Efficacy of grass pollen sublingual immunotherapy for three consecutive seasons and after cessation of treatment: the ECRIT study. Allergy. 2009;64:1394-401.

35. Novembre E, Galli E, Landi F, Caffarelli C, Pifferi M, De Marco E, et al. Coseasonal sublingual immunotherapy reduces the development of asthma in children with allergic rhinoconjunctivitis. J Allergy Clin Immunol. 2004;114:851-7.

36. Pajno GB, Caminiti L, Crisafulli G, Vita D, Valenzise M, De Luca R, et al. Direct comparison between continuous and coseasonal regimen for sublingual immunotherapy in children with grass allergy: a randomized controlled study. Pediatr Allergy Immunol. 2011;22:803-7.

37. Stelmach I, Kaluzinska-Parzyszek I, Jerzynska J, Stelmach P, Stelmach W, Majak P. Comparative effect of pre-coseasonal and continuous grass sublingual immunotherapy in children. Allergy. 2012;67:312-20.

38. Durham SR, Walker SM, Varga EM, Jacobson MR, $\mathrm{O}^{\prime}$ Brien F, Noble W, et al. Long-term clinical efficacy of grass-pollen immunotherapy. N Engl J Med. 1999;341:468-75.

39. Jacobsen L, Niggemann B, Dreborg S, Ferdousi HA, Halken S, Host A, et al. Specific immunotherapy has long-term preventive effect of seasonal and perennial asthma: 10-year follow-up on the PAT study. Allergy. 2007;62:943-8. 